\title{
Obstetrical complications among adolescent girls at the maternity ward of Ignace Deen National Hospital
}

\author{
Ibrahima Sory Balde*, Abdourahamane Diallo, Mamadou H. Diallo, Ibrahima Sylla, \\ Fatoumata B. Diallo, Mamadou S. Barry, Ibrahima T. Diallo, Telly Sy
}

Faculty of Health Science and Techniques, University of Conakry, Guinea

Received: 12 March 2020

Accepted: 04 April 2020

\section{*Correspondence:}

Dr. Ibrahima Sory Balde,

E-mail: baldeisory@yahoo.fr

Copyright: (C) the author(s), publisher and licensee Medip Academy. This is an open-access article distributed under the terms of the Creative Commons Attribution Non-Commercial License, which permits unrestricted non-commercial use, distribution, and reproduction in any medium, provided the original work is properly cited.

\section{ABSTRACT}

Background: The objective of this study was to highlight obstetrical complications that occurred among adolescent girls who delivered at the ward and to identify factors associated with the occurrence of such complications.

Methods: This was a prospective study of descriptive and analytical type extending over a period of one year from September 1, 2016 to August 31, 2017 carried out at the maternity ward of Ignace Deen National Hospital at Conakry Teaching Hospital (CHU). It covered a continuous series of 1034 deliveries among adolescent girls.

Results: The frequency of childbirth among adolescent girls was $16.7 \%$. The main complications identified were dystocia, severe preeclampsia, eclampsia, retroplacental hematoma, placenta previa, uterine rupture, severe anemia, postpartum hemorrhage and puerperal endometritis. These complications occurred among adolescent girls aged 18 to 19, christian, skin and pelvic bones secondary school or university students. Factors associated with such complications were the marital status $(\mathrm{p}=0.010)$, the gestational age $(\mathrm{p}=0.012)$, the number of prenatal consultations $(\mathrm{p}=0.001)$, the place of prenatal consultation $(\mathrm{p}=0.001)$, the reason for admission $(\mathrm{p}=0.000)$ and the mode of admission $(\mathrm{p}=0.000)$.

Conclusions: Childbirth among adolescent girls is frequent in this context; complications are numerous but they are preventable in the vast majority of cases.

Keywords: Adolescent girls, Ignace deen, Obstetrical complications

\section{INTRODUCTION}

Adolescent girl's pregnancy, also known as early pregnancy, is defined by the World Health Organization (WHO) as the occurrence of pregnancy in young people aged between 10 and $19 .{ }^{1}$

This phenomenon is becoming increasingly frequent in the world with each year, 150,000,000 young people aged 15 to 19 giving birth to a child, i.e. $10 \%$ of all births, most of which occurring in developing countries. ${ }^{2-4}$

While adolescent girls' pregnancy is considered a public health issue in Western countries, in developing countries, where $30 \%$ of women give birth during their teenage years, early motherhood is socially and culturally accepted. ${ }^{5}$

Early pregnancy is a high-risk situation for obstetric complications due to the physiological and sociological characteristics that condition the behaviour of this population group. ${ }^{1}$ Such complications can occur during pregnancy, but especially during childbirth and also after delivery, as individuals are immature, and they are growing physically, sexually and psychologically. ${ }^{1}$

The risk of obstetric fistula and maternal death is high if pregnancy occurs before the age of $20 .^{6}$ 
The high frequency of such early pregnancies and the resulting high risk of maternal morbidity and mortality prompted this study on "Obstetric Complications in adolescent girls at the maternity ward of Ignace Deen National Hospital". 6

\section{Objectives}

- To calculate the frequency of childbirth among adolescent girls at the ward during the study period

- To identify obstetrical complications that occurred among teenage girls who gave birth in the ward during the study period

- Describe the socio-demographic characteristics of adolescent girls who developed these complications

- Identify risk factors for such obstetrical complications.

\section{METHODS}

This was a prospective study of descriptive and analytical type extending over a period of one year from September 1, 2016 to August 31, 2017 carried out at the maternity ward of Ignace Deen National Hospital at Conakry Teaching Hospital. It covered a continuous series of 1,034 teenage deliveries.

\section{Inclusion criteria}

- Were included in the study all adolescent girls who delivered in the ward during the study period with or without obstetrical complications and who agreed to participate in the study.

\section{Exclusion criteria}

- Were excluded from the study all teenagers who did not agree to participate in it.

All teenagers who delivered in the ward during the study period were entirely recruited. This yielded a sample of 1034 adolescent girls, 343 of whom developed obstetric complications.

For the descriptive part of this study, we calculated proportions for the qualitative variables, the average, the standard deviation, the minimum and the maximum for quantitative variables.

For the comparison, adolescents were divided into two groups:

- Group1: composed of adolescent's girls who experienced obstetrical complications

- Group 2: composed of adolescent girls who did not experience any obstetrical complication.

The following parameters were compared between the two groups : adolescents' age, their marital status, their level of education, their age at marriage, their religion, their gestational age, their parity, their pregnancy term, the number of ANC they had, the ANC venue, the reason for admission and the mode of admission. For the comparison of proportions, we used Pearson's Chi2 test after checking its application conditions. The difference was considered significant when the p-value was less than $5 \%$.

From an ethical point of view, we sought and obtained prior authorization from the Head of Department and the Hospital's Ethics Committee. Informed patient consent, anonymity and confidentiality were respected.

\section{RESULTS}

\section{Frequency}

Among the 6184 deliveries performed at the ward during the study period, 1034 involved adolescent girls i.e. a frequency of $16.7 \%$.

Table 1: Breakdown of complicated cases by type of complication.

\begin{tabular}{|lll|}
\hline Type of complication & $\begin{array}{l}\text { Number } \\
\text { of people }\end{array}$ & $\begin{array}{l}\text { Percentage } \\
(\%)\end{array}$ \\
\hline In the course of labor & 343 & $74.89 \%$ \\
\hline Pre-eclampsia & 33 & $9.6 \%$ \\
\hline Eclampsia & 38 & $11.1 \%$ \\
\hline Dystocia & 201 & $58.6 \%$ \\
\hline HRP & 40 & $11.7 \%$ \\
\hline Placenta previa & 4 & $4.1 \%$ \\
\hline Uterine rupture & 1 & $0.3 \%$ \\
\hline Severe anemia & 8 & $2.3 \%$ \\
\hline Others & 8 & $2.3 \%$ \\
\hline Complication in postpartum & 115 & $25.11 \%$ \\
\hline Postpartum hemorrhage & 21 & $18.26 \%$ \\
\hline Endometritis & 10 & $8.7 \%$ \\
\hline Eclampsia & 12 & $10.43 \%$ \\
\hline High blood pressure & 27 & $23.5 \%$ \\
\hline Anemia & 44 & $38.3 \%$ \\
\hline Others & 1 & $0.9 \%$ \\
\hline Total & 458 & $100 \%$ \\
\hline
\end{tabular}

\section{Mode of childbirth among teenagers}

Out of the 1034 deliveries among adolescent girls, 627 deliveries by vaginal delivery $(60.6 \%)$ and 407 caesarean sections $(39.4 \%)$ were recorded.

\section{History of female genital mutilation}

Almost all adolescent girls have undergone genital mutilation with 1023 cases of excision $(98.93 \%)$ and 2 cases of infibulation $(0.19 \%)$. Only 9 adolescent girls $(0.87 \%)$ had not undergone genital mutilation. The complications encountered were more frequent during 
labor than in the postpartum, $74.89 \%$ versus $25.11 \%$. During labor dystocia remains the most frequently encountered complication, $58.6 \%$ followed by retro placental hematoma and eclampsia with $11.7 \%$ and $11.1 \%$ respectively. In the postpartum, anemia was the most common complication, $38.3 \%$ followed by hypertension and postpartum hemorrhage with $23.5 \%$ and $18.2 \%$ respectively.

\section{Adolescent girls' age}

The average age was 17.5 with a standard deviation of 1.2 , a minimum of 14 and a maximum of 19 . The most affected age group was the 18-19 years old group i.e. $34.5 \%$. The occurrence of obstetric complications was independent of the teenager's age $(\mathrm{p}=0.542)$.

Table 2: Breakdown of adolescent girls who developed obstetrical complications versus those who did not, according to the number of prenatal visits.

\begin{tabular}{|c|c|c|c|c|c|c|}
\hline \multicolumn{7}{|c|}{ Obstetrical complications } \\
\hline \multirow{2}{*}{ Number of PNCs } & \multicolumn{2}{|l|}{ Yes } & \multicolumn{2}{|l|}{ No } & \multicolumn{2}{|l|}{ Total } \\
\hline & No. & I (\%) & No. & I $(\%)$ & No. & I (\%) \\
\hline 0 & 7 & $70.0 \%$ & 3 & $30.0 \%$ & 10 & $100 \%$ \\
\hline 1 & 52 & $44.4 \%$ & 65 & $55.5 \%$ & 117 & $100 \%$ \\
\hline 2 & 88 & $38.8 \%$ & 139 & $61.2 \%$ & 227 & $100 \%$ \\
\hline 3 & 86 & $31.6 \%$ & 186 & $68.4 \%$ & 272 & $100 \%$ \\
\hline 4 & 82 & $29.5 \%$ & 205 & $73.7 \%$ & 287 & $100 \%$ \\
\hline 5 & 25 & $26.4 \%$ & 70 & $73.7 \%$ & 95 & $100 \%$ \\
\hline 6 & 3 & $11.5 \%$ & 23 & $88.5 \%$ & 26 & $100 \%$ \\
\hline Total & 343 & $33.2 \%$ & 691 & $66.8 \%$ & 1034 & $100 \%$ \\
\hline
\end{tabular}

Khi 2: 35, dll: 6, p: 0.001 .

\section{Marital status}

The frequency of obstetrical complications $(35.9 \%)$ was significantly higher among married adolescent girls than among unmarried adolescent girls (27.9\%) with $\mathrm{p}=0.010$.

\section{Occupation}

Secondary school and university students were the most affected with $39.5 \%$ followed by those in the liberal professions with $34.4 \%$.

Table 3: Breakdown of adolescent girls who developed obstetrical complications versus those who did not develop complications depending on the location where prenatal consultations took place.

\begin{tabular}{|lllllll|}
\hline Obstetrical complications & \multicolumn{2}{c|}{ Total } & \multicolumn{3}{c|}{ PNC } \\
\cline { 2 - 7 } Number of PNCs & Yes & $\mathrm{I}(\%)$ & No. & $\mathrm{I}(\%)$ & No. & $\mathrm{I}(\%)$ \\
\cline { 2 - 7 } & No. & $70.0 \%$ & 3 & $30.0 \%$ & 10 & $100 \%$ \\
\hline Unattended & 7 & $32.2 \%$ & 65 & $67.7 \%$ & 477 & $100 \%$ \\
\hline Health Center & 52 & $38.2 \%$ & 139 & $61.7 \%$ & 178 & $100 \%$ \\
\hline CMC & 88 & $12.3 \%$ & 186 & $87.6 \%$ & 81 & $100 \%$ \\
\hline CHU & 86 & $36.1 \%$ & 205 & $63.8 \%$ & 288 & $100 \%$ \\
\hline Private medical or clinical office & 82 & $33.7 \%$ & 691 & $66.8 \%$ & 1034 & $100 \%$ \\
\hline Total & 343 & & & & & \\
\hline
\end{tabular}

Khi 2: 26.92, dll: 4, p: 0.001 .

\section{Educational level}

No link was found between adolescent girls' educational level and the occurrence of obstetrical complications $(\mathrm{p}=0.100)$.

\section{Adolescent girls' age at marriage}

Obstetrical complications were not related to the teenagers' age at marriage $(\mathrm{p}=0.542)$. 


\section{Teenagers' age at first intercourse}

More than half (54.6) reported that they did not know their age at first intercourse, $14 \%$ said they were 16 years old and $13.5 \%$ said they were 17 years old.

\section{Religion}

Regardless of religion, the risk of obstetrical complications was the same for all teenagers $(p=0.612)$.

\section{Gestational}

The average number of pregnancies was one pregnancy with a standard deviation of 0.4 pregnancy, a minimum of one pregnancy and a maximum of 3 pregnancies. The frequency of obstetrical complications in parturient with two or three pregnancies $(41.9 \%)$ was significantly higher than that $(31.6 \%)$ found in primigravidae $(\mathrm{p}=0.012)$.

\section{Parity}

There was no significant association between the occurrence of obstetrical complications and parity among adolescent girls $(\mathrm{p}=0.060)$.

\section{Term of pregnancy}

Whatever the term of the pregnancy, the probability of obstetrical complications is identical $(\mathrm{p}=0.728)$.

The pregnancy follow-up study found that the lower the number of antenatal consultations, the higher the risk of obstetric complications, $70 \% ; 44.5 \%$ and $38.7 \%$ respectively for pregnant women who did not have any prenatal consultation and those with one (1) and two (2) prenatal consultations. The risk of these complications decreases as the number of antenatal consultations increases, $28.6 \% ; 26.3 \%$ and $11.5 \%$ respectively for pregnant women who carried out four (4), five (5) and six (6) prenatal consultations. The differences observed were statistically significant $(\mathrm{p}=0.001)$.

The study of the location of antenatal consultations reveals that obstetric complications occur more frequently in pregnant women followed in peripheral maternity hospitals and in private practices and clinics with respectively $32.2 \%$ (health center), $38.2 \%$ (CMC) and $36.1 \%$ (private practice and clinic) unlike pregnant women followed in the CHU (12.3\%) with a statistically significant difference.

Table 3: Breakdown of adolescent girls who developed obstetrical complications versus those who did not depending on the reason for admission.

\begin{tabular}{|c|c|c|c|c|c|c|}
\hline \multicolumn{7}{|c|}{ Obstetrical complications } \\
\hline \multirow{2}{*}{ Admission reason } & \multicolumn{2}{|l|}{ Yes } & \multicolumn{2}{|l|}{ No } & \multirow{2}{*}{$\begin{array}{l}\text { Total } \\
\text { No. }\end{array}$} & \multirow{2}{*}{$\begin{array}{l}\text { PNC } \\
\mathrm{I}(\%)\end{array}$} \\
\hline & No. & $\mathrm{I}(\%)$ & No. & $\mathrm{I}(\%)$ & & \\
\hline Labor & 151 & $18.4 \%$ & 669 & $81.6 \%$ & 820 & $100 \%$ \\
\hline Dystocia & 117 & $90.7 \%$ & 12 & $9.3 \%$ & 129 & $100 \%$ \\
\hline Hemorrage & 55 & $98.2 \%$ & 1 & $1.8 \%$ & 56 & $100 \%$ \\
\hline Others & 20 & $69.0 \%$ & 9 & $31.0 \%$ & 29 & $100 \%$ \\
\hline Total & 343 & $33.2 \%$ & 691 & $66.8 \%$ & 1034 & $100 \%$ \\
\hline
\end{tabular}

Khi 2: 396.762, ddl: 3, p: 0.000 .

Table 5: Breakdown of adolescent girls who developed obstetrical complications versus those who did not depending on the mode of admission.

\begin{tabular}{|c|c|c|c|c|c|c|}
\hline \multicolumn{7}{|c|}{ Obstetrical complications } \\
\hline \multirow{2}{*}{ Admission mode } & \multicolumn{2}{|l|}{ Yes } & \multicolumn{2}{|l|}{ No } & \multirow{2}{*}{$\begin{array}{l}\text { Total } \\
\text { No. }\end{array}$} & \multirow{2}{*}{$\begin{array}{l}\mathrm{PNC} \\
\mathrm{I}(\%)\end{array}$} \\
\hline & No. & $\mathrm{I}(\%)$ & No. & $\mathrm{I}(\%)$ & & \\
\hline Coming from home & 256 & $29.4 \%$ & 614 & $70.6 \%$ & 870 & $100 \%$ \\
\hline Evacuee & 87 & $53.0 \%$ & 77 & $47.0 \%$ & 164 & $100 \%$ \\
\hline Total & 343 & $33.2 \%$ & 691 & $66.8 \%$ & 1034 & $100 \%$ \\
\hline
\end{tabular}

Khi 2: 34.738, ddl: 1, p: 0.000 .

Birthing labor was the most frequent reason for admission among pregnant women who did not present obstetric complications, the opposite result in pregnant women who presented obstetric complications $(81.6 \%$ versus $18.4 \%$ ). However, hemorrhage and dystocia were the most frequently encountered obstetric complications, $98.2 \%$ and $90.7 \%$ respectively in the population that manifested obstetric complications versus $1.8 \%$ and $9.3 \%$ in those who did not show any complications. The differences observed were statistically significant. Compared to the mode of admission, the risk of obstetric complications is higher in evacuated adolescents, 53\% versus $29.4 \%$, the differences observed were statistically significant $(\mathrm{p}=0.00)$. 


\section{The reason for evacuation}

More than half of adolescent girls (56.7\%) were evacuated for dystocia, followed by acute fetal distress $(12.8 \%)$ and hemorrhage with $11.6 \%$.

\section{Status of the new born at birth}

Live births were by far the most frequent with $91.3 \%$ against $8.7 \%$ of stillbirths.

\section{Apgar score at the $5^{\text {th }}$ minute}

A total $86.4 \%$ good Apgar $(\geq 7)$ and $13.6 \%$ bad Apgar $(<7)$ were recorded.

\section{Maternal death}

Study recorded 14 cases of maternal death with a lethality of 14.50 per thousand and a ratio of 1480 deaths per 100,000 live births.

\section{DISCUSSION}

\section{Frequency of childbirth among teenagers}

During the study period, we recorded 1034 adolescent deliveries out of a total number of 6184 deliveries at the ward, i.e. a frequency of $16.7 \%$.

The frequency of childbirth varies depending on the country and the age limits considered. ${ }^{7}$

West Africa is a major contributor with a frequency of $8 \%$ compared to East Asia where it was $5.5 \% .^{8}$

Study rate of $16.7 \%$ is lower than those of some authors, notably: N'Guembi et al $(30.3 \%)$ in Central Africa. ${ }^{9}$ Tebeu et col $(26.5 \%)$ in Cameroon. ${ }^{10}$

On the other hand, this rate is higher than those reported by certain African and European series, notably: Traoré B $(15.5 \%)$ in Mali, Nayama M $(10.9 \%)$ in Niger; Hamada $(2.6 \%)$ in Morocco and Soula $(1.55 \%)$ in French Guyana. ${ }^{1,11-13}$ This difference could be explained by several reasons in particular: the early marriage in Africa linked to cultural, ethnic and religious factors (40 to $50 \%$ of married girls aged 13 to 15 ), poverty and illiteracy. ${ }^{14}$

\section{Frequency of obstetric complications among adolescent girls}

Out of a total of 6184 deliveries, including 1034 deliveries among adolescent girls, study recorded 343 cases of obstetric complications, i.e. $5.54 \%$ of all deliveries and $33.17 \%$ of deliveries among adolescent girls. This rate is lower than the one reported by Foumsou et al, (12.8) In Chad. ${ }^{15}$

\section{Mode of delivery}

The majority of births occur by natural routes, corresponding in this study to $60.6 \%$ in accordance with the literature. ${ }^{16}$

The old notion that deliveries through pelvises that may not be fully grown could expose a disproportionate risk of disproportion and caesarean section is not borne out in practice.

It is possible, as described by Jolly quoted by Dedeker et al, that adolescent girls may benefit from improved myometrial function and tissue elasticity facilitating vaginal delivery. ${ }^{17}$

Study results are similar to those of Foumsou et al in Chad, reporting $82.5 \%$ of deliveries by vaginal route, compared with $17.5 \%$ by caesarean section. ${ }^{15}$

\section{Socio-demographic characteristics}

Age

The average age of adolescent girls was 17.5 with extremes of 14 and 19 , i.e. a standard deviation of 1.2 years.

The incidence of obstetrical complications among adolescent girls increases as they advance in age: $27.5 \%$ for the 14-15 age group; $32.8 \%$ for the 18-19 age group, in contrast to the control population, where the risk of obstetrical complications decreases as age advances.

The observed differences were not statistically significant $\mathrm{p}=0.52$.

The high risk of obstetrical complications in the 18-19 years old age group could be explained by the fact that pregnancy occurs most frequently in this age group during adolescence.

\section{Marital status}

The incidence of obstetrical complications is higher among married adolescent girls compared to unmarried teenagers, i.e. $35.9 \%$ versus $27.9 \%$ with a statistically significant difference $(p=0.0010)$. Study result could be explained by the fact that our predominantly Muslim society has customs and traditions that impose marriage before the occurrence of a pregnancy, an out-of-wedlock pregnancy being considered a crime or a family dishonor, as sexual initiation is in most cases related to marriage. In developed countries and some emerging countries in Africa, most adolescent girls are unmarried, contrary to our countries that are predominantly Muslim, especially in Guinea, where the trend towards early fertility is voluntary and considered a means of strengthening the bonds of the couple and the stability of young spouses. ${ }^{18}$ 
Study series confirms this, given that the majority of our teenagers were married $(66.05 \%)$ and that pregnancy is desired.

It should also be noted that the rate of single people is gradually increasing in our country without reaching the figures for industrialized countries where sexual initiation is not linked to marriage.

\section{Occupation}

Occupation is an important factor in the outcome of adolescent girls' pregnancy, particularly for housewives and students who are not engaged in income-generating activities. In our series, $39.4 \%$ of the adolescent girls were secondary and university students and $25.4 \%$ were housewives.

Most comparative studies have found a difference in socio-economic status between pregnant adolescent girls and their adult counterparts; some studies have even identified it as a risk factor for early motherhood. Lesser, cited by Abbadi, suggests that these young girls find pregnancy as a way to enhance their self-esteem, gain respect, and ultimately escape this difficult social context. ${ }^{16}$ Other authors, however, are much less categorical, such as Narrigue, cited by Soula, who reports that the phenomenon can affect all social classes and that therefore socio-economic status does not play a strong determining role in the occurrence of adolescent girls' pregnancies. ${ }^{13}$ This high rate of adolescent girls at home $(25.4 \%)$ could be explained by the low rate of teenage girls attending school and the distrust of husbands to let their wives undertake other activities outside the home.

\section{Level of education}

adolescent girls with a low level of education or who are not attending school were the most exposed to obstetric complications, with an incidence of $38.4 \%$ and $34.5 \%$ respectively, and these complications decrease as the level of education increases. This is the corollary of illiteracy, with illiterate and ignorant women with a pronatalist conception wanting to have children from puberty to menopause.

Study high rate of out-of-school adolescent girls (39.7\%) is said to be in line with that of the general Guinean population, where $74 \%$ are illiterate, $85.33 \%$ of whom are female. ${ }^{19}$ This fact would be related to:

- The reluctance of parents who will be left to do all the housework.

- Parents' fear of abandoning traditional customs and morals

\section{Age at marriage}

The analysis of this parameter reveals that the majority of adolescent girls got married at the age of 18-19, i.e.
$57.93 \%$. Obstetrical complications also occur frequently in this age group, i.e. an incidence of $34.1 \%$.

According to Diallo FB this age at marriage in our country varies according to ethnic groups, and the lowest age at marriage (below 15 years) has been found among the Peulh ethnic group, where the young girl often sees her first menstrual period only in the family home, the second appearance being in the husband's home, and sometimes pregnancy occurs during the first intercourse. ${ }^{20}$

\section{Age at first sexual intercourse}

It appears from the study that the first sexual intercourse takes place in most cases at the age of 16 followed by the age of 17 with respectively $28.52 \%$ and $28.04 \% .11 .21 \%$ of women did not want to engage in this question, which is, most often, a taboo.

Early sexual intercourse is partly related to early marriage and the collapse of certain traditional values.

\section{Religion}

The analysis of this parameter shows that our teenage adolescent girls' girls are mostly Muslim (96.61\%). This percentage of Muslims is related to that of the different religious groups in Guinea, where $95 \%$ of the population practice Islam. $^{19}$

\section{Antecedents gestity}

The average gestity in the whole sample was one (1) with extremes of one (1) and 3 pregnancies, a standard deviation of 0.4 pregnancy.

The risk of obstetrical complications was higher in among adolescent girls who had been pregnant more than once (pauci gesture) i.e. $41.9 \%$ versus $31.6 \%$ incidence in primigravidae with a significant difference $(\mathrm{p}=0.012)$. Thus, gesture is a risk factor for obstetrical complications among adolescent girls.

\section{Parity}

The average parity in the whole sample was 1 the delivery with extremes of 1 and 3 deliveries, a standard deviation of 0.4 delivery.

The risk of obstetrical complications was higher among adolescents who had already been mothers (pauci pare) than those who were at their first delivery (primi pare), i.e. $40 \%$ versus $32.1 \%$ incidence without a statistically significant difference $(\mathrm{p}=0.06)$. Study results agree with those of $\mathrm{Bah} \mathrm{MH}$, and cervix "one of the most serious issues is undoubtedly the risk of new pregnancy in a very young mother making the teenager, as is often seen in our societies, the mother of 2 or 3 children". ${ }^{14}$ 
Study adolescent girls had a history of female genital mutilation in $99.12 \%$, genital mutilation dominated by excision $(98.93 \%)$. Yet excision is a traditional practice, having no basis with the Muslim religion, contrary to what many people think.

At the national level, measures are currently being considered to curb this scourge.

\section{Term of pregnancy}

The analysis of this parameter reveals that the risk of obstetrical complication is about the same whether the pregnancy is at term or not, i.e. $33.1 \%$ versus $35.6 \%$ with no statistically significant difference.

\section{Number of prenatal consultations}

The analysis of the pregnancy follow-up showed that the lower the number of prenatal consultations, the higher the frequency of obstetrical complications, i.e. $70 \% ; 44.44 \%$ and $38.76 \%$ respectively for gestants who had no prenatal consultation and those with one (1) and two (2) prenatal consultations. The frequency of these complications decreases as the number of prenatal consultations increases, i.e. $73.74 \% ; 73.68 \%$ and $88.48 \%$ respectively for pregnant women who have had four (4), five (5) and six (6) prenatal consultations. The differences observed were statistically significant $(\mathrm{p}=0.001)$.

The different age-related risks are associated with a significant risk of late detection of complications related to unattended pregnancies.

In general, prenatal monitoring was not of good quality in study series. This poor quality of prenatal monitoring could be explained by:

- The late notification of pregnancy, either because it is unwanted or hidden from the entourage.

- The lack of information on the importance of prenatal consultations in the monitoring of pregnancy and prognosis of childbirth.

But better than the number of prenatal consultations, it is rather the quality of the prenatal consultation that is of prime importance

\section{Venues of prenatal consultations}

The analysis of this parameter reveals that obstetrical complications occur more frequently in pregnant women attended in peripheral maternity hospitals and in private practices and clinics with respectively $32.2 \%$ (health centre), $38 \%$ (CMC) and $36.1 \%$ (private practices and clinics) as opposed to pregnant women attended in the Teaching Hospital -CHU- (17.2\%) with a statistically significant difference. This result could be explained by the fact that in the CHU antenatal consultations are carried out by specialist doctors, whereas in peripheral maternity hospitals, antenatal monitoring is most often carried out by paramedical staff, including in private facilities, most of which are clandestine.

\section{Mode of admission}

The analysis of this parameter reveals that the risk of obstetrical complications is higher among transferred adolescent girls, i.e. $52 \%$ versus $29.4 \%$, the differences observed were statistically significant $(\mathrm{p}=0.00)$.

\section{Reason for admission}

Labour was the most frequent reason for admission in pregnant women who had not had any obstetrical complications, with the opposite result in pregnant women who had had obstetrical complications $(81.6 \%$ versus $18.4 \%$ ). However, hemorrhage and dystocia were the most common obstetrical complications, 98.2\% and $90.3 \%$ respectively in the study population versus $1.8 \%$ and $9.3 \%$ in the control population. The differences observed were statistically significant $(\mathrm{p}=0.00)$.

\section{Reason for evacuation}

The most frequent reason for transfer was dystocia (41.46\% of transferees), followed by delivery labour and bleeding (15.24\% and $11.59 \%$ respectively).

\section{Prognosis}

\section{Maternal prognosis}

\section{Maternal morbidity}

Complications encountered were more frequent during labour than in postpartum, i.e. $74.89 \%$ versus $25.11 \%$. During labour, dystocia remains the most frequent complication encountered, i.e. $58.6 \%$, followed by retroplacental haematoma and eclampsia with $11.7 \%$ and $11.1 \%$ respectively.

In the postpartum period, anaemia was the most frequent complication, $38.3 \%$, followed by high blood pressure and postpartum hemorrhage with $23.5 \%$ and $18.26 \%$ respectively. Study results are different from those reported by some authors, notably Foumsou. L in Chad, reporting perineal tearing and eclampsia during labour and postpartum haemorrhage. ${ }^{15}$ Maternal age is a statistically established risk factor for vascular-renal syndrome (high blood pressure, preeclampsia, eclampsia, retroplacental haematoma), and the literature insists on taking age into account in its prevention. ${ }^{1}$

\section{Maternal mortality}

Study recorded 14 cases of maternal deaths, i.e. a lethality of 14.50 per thousand and a ratio of 1480 deaths per 100,000 live births. The causes of such deaths were 
dominated by hypovolemic shock due to postpartum hemorrhage (7 cases), retroplacental hematoma ( 2 cases), placenta previa (1 case), eclamptic state (3 cases) and puerperal infection (1 case). The maternal death ratio of teenagers in study series was lower than those reported by Nguessan in Côte d'Ivoire, Lankoandé in Ouagadougou and Mwobodo in Nigeria, which are respectively: 4040 deaths per 100,000 live births; 4081 deaths per 100,000 live births; 5415 deaths per 100,000 live births. ${ }^{21-23}$

Study adolescent girl's maternal death rate was higher than those of Traoré in Segou, Mali, and Nayama in Niamey, which reported $0.3 \%$ and $0.6 \%$, respectively. ${ }^{11,12}$

The high maternal mortality in our series could be partly explained by the lack of blood products as $64.3 \%$ of maternal deaths were due to haemorrhage.

According to Nwobodo and Panti, eclampsia is the leading cause of death in teenage girls $(53.9 \%) .{ }^{23}$ On the other hand, it has often been revealed in our context that delay in the management of obstetric emergencies (late obstetric evacuation; lack of kits; occupied operating theatre) was the main factor favoring maternal deaths in general.

\section{Prognosis of the new-born}

Study recorded $91.25 \%$ live births against $8.74 \%$ mortality with 18 twin deliveries.

The Apgar score is one of the determining factors in the morbidity of the newborn. The adaptation of the newborn to ectopic life was good (Apgar greater than or equal to 7 ) in $78.80 \%$ and poor in $12.45 \%$ of cases within 5 minutes of life.

Study recorded 92 cases of stillbirths, i.e. a rate of $8.74 \%$. The causes of this stillbirth were broken down as follows:

- $\quad$ Prematurity 22 cases $(23.91 \%)$

- Severe malaria in the mother 6 cases $(6.52 \%)$

- Pre-eclampsia and eclampsia 46 cases $(50 \%)$

- And retroplacental hematoma 18 cases (19.56\%).

All the authors agree that the young age of the mother plays a role in fetal prognosis, as the frequency of perinatal mortality is higher among newborns born to adolescent girls. ${ }^{24}$

\section{CONCLUSION}

The frequency of childbirth among adolescent girls was $16.7 \%$. Obstetrical complications encountered among such adolescent girls were dominated by dystocia, $3^{\text {rd }}$ quarter hemorrhage, post-partum hemorrhage, preeclampsia and eclampsia. These complications concerned adolescent girls aged 18 to 19, Christian, and skin and skin lesions secondary school or university students. Factors associated with such complications were marital status, gestational age, number of prenatal consultations, venue of prenatal consultation, reason and mode of admission.

\section{Funding: No funding sources}

Conflict of interest: None declared

Ethical approval: The study was approved by the Institutional Ethics Committee

\section{REFERENCES}

1. Hamada H, Zaki, Nejjar H, Filalia A, Chribi C, Brzadr, Alaouim T. Teenage pregnancy and childbirth in teenage girls: characteristics and profile about 311 cases. J Gynecol Obstet Biol Reprod. 2004;33(7):607-14.

2. Could J, Blackwel T, Heilig C, Axley M. Utility of percentage of births to teenagers as a surrogate for the teen birth rate. Am I Public Health. 1998;88(6):908-12.

3. Taylor D, Chavez G, Habra A, Boggess J. Risk factor for adult paternity in births to adolescents. Obstet Gynecol. 1997;89(2):199-205.

4. Lakouama A. Outcome of pregnancy and childbirth in teenage girls at the HGRN maternity hospital about 4586 cases collected in 5 years. Thesis Med Fac Med Univer Ndjamena. 2001;0016:83.

5. Combe JC, Reynauld. Adolescents and maternity in Reunion. Pediatrician's Magazine. 1998:261-264.

6. Fomulu JN, Ngassa PN, Nong T, Nana P, Nkwabong E. Maternal mortality at the Maternity Hospital and University Centre of Yaounde, Cameroun: 5-year retrospective study (2002-2006). Health Sci Dis. 2009;10:1.

7. UNFPA. Maternal reproductive and sexual health: reproductive health; 2010. Available at: https://www.unfpa.org/sites/default/files/pubpdf/uarh_report_2010.pdf. Accessed $10^{\text {th }}$ February 2020.

8. Kowalski-Morton S. Young people count down. 2015:70-7.

9. Nguembi E, Yonza MC, Sepou A, poussomandi MA, Nani MN, Zohou T. Teenage pregnancy in the town of Bouar (Central Africa). Médecine d'Afrique Noire. 2005;52(12):681-5.

10. Tebeu PM, Tantchou J, Obama Abena MT, Mevoula Onalad, Leke JR. Childbirth of adolescent girls in the far north of Cameroun. Revue Médicale de Liège. 2006;19:124-7.

11. Traoré B, Kokaina C, Beye SA, Mounkoro N, Tegueté I, Traoré M, et al. Childbirth among teenage girls in the maternity ward of the Ségou hospital in Mali. Médecine d'Afrique Noire. 2010;57:450-4.

12. Nayama M, Dan Malan Bouzou R, Nayoussa M. Management of childbirth among adolescent girls at the Issakaga Zobi maternity hospital in Niamey. Retrospective study on 976 observations over 3 years. Médecine d'Afrique Noire. 2007;54(7):413-8. 
13. Soula O, Carles G, Largeaud M, Guidi W, Montoya Y. Pregnancy and childbirth in adolescents under 15 years of age. Study of 181 cases in French Guyana. J Gynécol Obstet Biol Reprod. 2005;35:53-61.

14. Bah MD, Pellegrin M, Thioume O. Adolescence and pregnancy (psychosocial and medical approach). Medicine Afrique Noire. 2001;9:115-22.

15. Foumsou L, Gabkika BM, Saleh A, Memadji M. Obstetrical complications among adolescent girls at the maternity of National Reference Hospital (HGRN) of N'Djamena. Med Black Africa. 2014;61:442-7.

16. Abbadi S. Childbirth among adolescents: Retrospective study of 290 cases in adolescents aged between 15 and 18 in the maternity ward of Ghassini Hospital in Fez. Thesis of Med. 2009; $\mathrm{N}^{\circ} 080: 6-11$.

17. Dedeker F, De Baillien Court T, Fortier D, Gerardin P. Study of obstetrical risk factors in the monitoring of 365 teenage primiparous pregnancies on Reunion Island. J Gynaeco-Obstet Reprod Biol. 2005;34(1):694-701.

18. Iloki LH, Kaubaka R, Itona C, Montonnau M. Teenage pregnancy and childbirth in Congo; about 276 cases at Brazzaville University Hospital. J Gynaco-obstét Reprod Biol. 2004;33(1):37-42.

19. Ministry of Planning Conakry-Guinea: National Institute of Statistics: Demographic Health and Multiple Indicator Cluster Survey (EDS-mics 2012) Calverton, Maryland, USA; 2013.

20. Diallo FB, Diallo MS, Bangoura S, Camara Y, Diallo AB. Medical problems in adolescent childbirth at the gynaecological-obstetrical clinic of the CHU Ignace Deen. Guinée Méd. 1996; 14:3943.

21. N'Guessan E, Bouhoussou PE, Touré B, Djanhan L, Tegnan JA, Guie P et al. Risk factor for adolescent maternal mortality. About 60 cases collected at the gynaecology and obstetrics department of the CHU of Treichville, Ivory Coast. Med Afr Noire. 2010;51:521-6.

22. Lankoande J, Ouédraogo CMR, Ouédraogo A, Thieba B, Akotionga M, Sanou J et al. Maternal mortality among adolescents at the CHU of Ouagadougou. Rev Méd de Bruxelles. 1999;20:87-9.

23. Nwobodo EI, Panti A. Adolescent maternal mortality in North West Nigeria. West Afr $\mathbf{J}$ Med. 2012;31:224-6.

24. World Health Organization (WHO). Pregnant Adolescents: Bringing the Promise of Hope Worldwide; 2007. Available at: https://apps.who.int/iris/bitstream/handle/10665/433 68/9241593784_eng.pdf?sequence $=1$. Accessed $10^{\text {th }}$ February 2020.

Cite this article as: Balde IS, Diallo A, Diallo MH, Sylla I, Diallo FB, Barry MS, et al. Obstetrical complications among adolescent girls at the maternity ward of Ignace Deen National Hospital. Int J Reprod Contracept Obstet Gynecol 2020;9:188694. 